\title{
LESÃO DE CÉLULAS GIGANTES CENTRAL
}

Keli Cristina BERNARDO, Eduardo MORESCHI, Cleverson Luciano TRENTO, Vilmar Divanir GOTTARDO, Renato ZARDETTO JUNIOR

A lesão de células gigantes é de etiologia ainda desconhecida, provavelmente decorrente de algum trauma, embora este nem sempre possa ser facilmente evidenciado. É apresentado um caso de lesão de células gigantes central, tendo natureza traumática, em paciente leucoderma do sexo feminino com 22 anos de idade, com tumefação envolvendo dentes inferiores anteriores. Exames radiográficos incluindo tomografia em cortes axiais e coronais foram realizados, evidenciando área hipodensas e hiperdensas com aspecto multilocular sugerindo diagnóstico diferencial de ameloblastoma, cisto ósseo aneurismático, displasia fibrosa e lesão de células gigantes. Foi realizada biópsia, identificando-se à microscopia de luz presença de células gigantes multinucleadas e grupos de fibras colágenas com áreas de extravasamento de eritrócitos e depósitos de hemossiderina. Para o diagnóstico definitivo, foram realizados exames bioquímicos do sangue para dosagem de fosfatase alcalina, níveis de cálcio e fósforo, e dosagem de paratormônio, verificando-se, em todos eles, valores de referência em níveis normais. O tratamento adotado foi curetagem cirúrgica da lesão com exodontia dos dentes envolvidos no processo. O controle pósoperatório de três anos não apresentou sinais de recidiva.

Palavras-chave: Curetagem; Tumor de células gigantes do osso; Extração dentária. 